\title{
Marketing Health and Social Marketing the Importance of Public Health Campaigns to Create Public Awareness in Turkey
}

\author{
Prof. Dr. Emrah Cengiz \\ Dr. Esma Gültüvin Gür Omay
}

\author{
Doi:10.5901/mjss.2013.v4n10p325
}

\begin{abstract}
Every year globally, public health campaigns are launched. These public health campaigns carry the aim of improving health behavior and creating public awareness on health. In the globalised world, health marketing can be defined as delivering health information through consumer - based strategies in order to promote public awareness. In this paper, we analyze the effectiveness of these campaigns to change health behavior .In Turkey, smoking and tobacco use has been a very serious health problem since years. In this context, The Ministry of Health launched a social marketing campaign in order to create public awareness against smoking. This campaign has been a successful campaign to create public awareness against smoking and tobacco use. In this paper, our purpose is to analyze the campaign against tobacco use of The Ministry of Health to what extend it created public awareness.and the success of the campaign.
\end{abstract}

Keywords: social marketing, public awareness, public health campaigns against tobacco use, Turkey.

\section{Introduction}

Globalisation brought new perspectives on societal level. The changing nature of social life and difference in life styles made it necessary to adopt new strategies. Marketing is one of those key areas in developing new strategies. The introduction of social marketing made it possible to achieve social ends on issues like health. Social marketing began to comprise the social causes. Because campaigns that are launched without taking the market conditions into consideration remained ineffective. So, social marketing developed sophisticated methods to achieve ends in social causes. Every year public health campaigns are launched to create public awareness and to achieve social ends in public health marketing. In Turkey, the campaigns on smoking and tobacco use remained ineffective until the Ministry of Health developed a successful social marketing campaign on smoking and tobacco use.

\section{Health marketing: A General Outlook}

The globalisation marked a itself as a phase when dramatic changes took place in every aspect of life such as life styles, personal habits etc. As the techniques and scientific developments in health improved, the shift from curing infections to preventing chronic disesases started. Because the globalisation made a drastic change in lifestyles starting from 1970s onwards. Chronic diseases increased due to changes in life styles and personal habits. Therefore; preventive health and public health gained importance. Based on that, being physically active, quitting smoking and drinking, staying away from stress, dieting, getting preventive health services become key elements in staying healthy. Educating public and improving public health gained ground in the concept of health. While educating the public seemed an important goal, the ways to achive it remained a problem. Public health experts looked in the area of marketing and communication to develop effective programs to implement public health education programs.

In the field of marketing, it all started when the famous question was asked by Wiebe "Why can't you sell brotherhood like you sell soap?" He argued that when it came to the concept of selling social causes the strategies developed could be feeble. Social campaigns that are conducted without taking market conditions into consideration are rather ineffectual. He analyses four social campaigns and the reasons to their success or lack of successs. In his article "he found that the more the conditions of social campaign resembled those of a product campaign the more succesful the social campaign would be" (Kotler and Zaltman, 1971: 3). This marked a shift from classical marketing techniques where commodities are simply being sold and enlarged the area of marketing. The marketing industry began to develop more sophisticated methods and techniques to meet the demands of differentiated markets where the concept of 'product' is 
broadened to include social issues as well. Therefore, the role of the consumer is foregrounded when the social issues are included in the marketing process, giving the field of marketing new areas of study such as social marketing.

\title{
3. What is Social Marketing?
}

In marketing literature one of the popular areas of discussion is social marketing. The reason why social marketing gained popularity is that there is an increasing degree of social responsibility in the socities world wide. Because the needs and interests of the socities change day by day. Social marketing exceeds one dimensional marketing and it is rather related with the multi faceted levels of marketing. The term social marketing is defined in the dictionary of American Marketing Association as follows;

\begin{abstract}
"1. (environments definition) The branch of marketing that is concerned with the use of marketing knowledge, concepts, and techniques to enhance social ends, as well as the social consequences of marketing strategies, decisions, and actions. 2. (social marketing definition) Marketing designed to influence the behavior of a target audience in which the benefits of the behavior are intended by the marketer to accrue primarily to the audience or to the society in general and not to the marketer. Comment: Social marketing is sometimes confused with social impact of marketing. Social marketing can be carried on by for-profit, public, and private nonprofit organizations or by individuals. Examples would be attempts to influence individuals to stop smoking (by the private nonprofit American Cancer Society) or report crimes (by the public U.S. Department of Justice). An attempt of one friend to influence another to go on a diet is also social marketing" (www. marketingpower.com).
\end{abstract}

The term 'social marketing' is introduced by Philip Kotler in 1971. Philip Kotler and Gerald Zalman in their article titled "Social Marketing: An Approach to Planned Social Change" defined social marketing as "the design, implementation and control of programs calculated to influence the acceptibility of social ideas and involving considerations of product, planning, pricing, communication, distribution and marketing research. They introduced social marketing as the 'promising framework for planning and implementing social change' (Kotler and Zalman, 1971: 3) which indeed opened new areas of study in designing social change. In this case, the marketing principles and techniques are used to influence social change. In order to do this, the target audience is aimed by using marketing techniques to accept or change behavior for the sake of the society. As noted by Kotler et al.,

"Social marketing is the use of marketing principles and techniques to influence a target audience to voluntarily accept, reject, modify or abandon a behavior for the benefit of individuals, groups or society as a whole" (2002: 5).

Although the same techniques are used there is a specific difference between social marketing and commercial marketing. Social marketing differs from commercial marketing in the scope of their gains as one is financial the other is societal or individual (Kotler et al., 2002: 8). It is also argued that there is a kind of poetic justice in social marketing by borrowing the techniques used in commercial marketing used to promote cigarettes, alcohol and other harmful products and using them again for the benefit of society(Walsh et al.,1993:107).

Hence, Kotler et al. argues that by social marketing they are selling a behaviour change that is voluntary and this behavior change brings benefits to the society on the whole.(2002:5-8) This behavior change is tried to be obtained by using methods drawn from marketing theory as well as behavior theory, psychology and communication theory. One of these methods include using 4Ps of marketing that include place, price, product and promotion in aiming behavioral change in the society. The integration of the 4Ps i.e the marketing mix is the important element in a social marketing campaign. Because it is the 'mix that matters most' (cited from Bill Smith by Kotler and Lee, 2009:185).

Social marketers use 4Ps to reach their targeted behaviors. The 4Ps should start to be developed with the order of product, price, place, promotion. Because each follows in sequence the other. The mix of the 4Ps creates a synergy together that makes a successful campaign possible. The product should be clearly defined to make the strategy successful. The product can be divided into three sub categories such as the core product (the benefits the audience will experience), the actual product (the desired behavior), the augmented product (helps perform the targeted behavior). Price includes the prices that target audience should pay to achieve desired behavior change such as time effort, energy or physical discomfort. Place is where the audience will obtain services related to the campaign. Lastly, promotion includes effective communications to tell the audience the scope of the project and various communication channels are used such as advertising public relations, events sponsorships, and personal selling and word of mouth. Media channels they can be online or offline, or both (Cheng et al, 2011:10). In this respect, online media includes online material from 
web sites to blogs and and offline media includes the print media and radio and television as well as billboards and other material related to it.

As mentioned earlier, social marketing tries to make behavioral change in the audience by selling behavior to them. The four major areas that social marketing focuses on are; health promotion on issues such as smoking and tobacco, drinking, obesity, eating disorders, cancers etc., environmental protection on issues such as air pollution, water conservation, litter, forest destruction etc., safety on issues such as domestic violence, drinking and driving, gun storage etc, community related issues such as voting, literacy etc. (Cheng et al, 2011:3). Social marketing campaigns concerning public health is more concentrated when compared to other fields of social marketing because public health issues affect the society as a whole concerning health.

\section{Social Marketing to Improve Public Health}

Social marketing paved the way in solving health problems by providing powerful tools to public health. International public health campaigns were launched in the early years of social marketing in third world countries on issues like sanitation, immunization, family planning, nutrition etc. (Walsh et al, 1993: 107). In 1980s WHO (World Health Organization) started to use the term social marketing and began to promote social marketing in areas of public health and in public health problems world wide. With the incorporation of all the strategies of social marketing the public health practitioners found an effective way of promoting health through out the world. Social marketing is used and developed for the campaigns for smoking, drug use, preventing chronic diseases, infant mortality etc. Therefore, public health promoters found an effectual method of changing health behavior.

When we talk about social marketing for health we see it is not only health communication. It is the synergy that surrounds all those strategies:

"Social marketing is widely used to influence health behaviour. Social marketers use a wide range of health communication strategies based on mass media; they also use mediated (for example, through a healthcare provider), interpersonal, and other modes of communication; and marketing methods such as message placement (for example, in clinics), promotion, dissemination, and community level outreach. Social marketing encompasses all of these strategies" (Evans, 2006: 1207).

As social marketing encompasses all of those strategies, it is obvious that social marketing is a dynamic and continous process as shown in Figure 1. But it should be noted that social marketing comprises many elements and when all those elements come together social marketing becomes meaningful.

Figure 1. Social Marketing Wheel

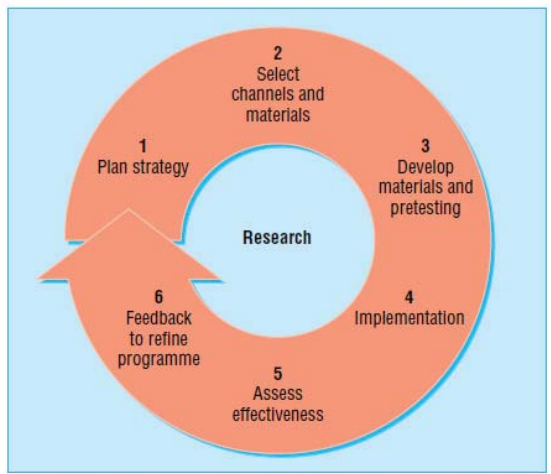

Source: Evans, 2006: 1207.

The six stages of social marketing can be summarized as follows; firstly plan strategy is developed, and then channels and materials are selected to develop behavior change along with the materials and pretesting, implementing the campaign and assesing the effectiveness of the campaign whether it creates public awareness or not such as giving up 
smoking (behavior change) and lastly getting feedback to reinforce the programme. The social marketing wheel is in the shape of an eternal circle one stage giving way to the other (Evans, 2006: 1207). This shows the structure of social marketing that supports development and betterment in the society. Because feedbacks are important keys in specifying the strategies that follows. In short, it can be suggested that social marketing is in harmony with Kaizen philosophy.

On the other hand it has to be kept in mind that a successful social marketing campaign lies in the utilization of different formats of communication and media usage of media channels. They cover a great range of formats and channels from advertising to sponsorships and personal communication. As Wakefield puts it;

\begin{abstract}
"Media campaigns can be of short duration or may extend over long periods. They may stand alone or be linked to other organised programme components, such as clinical or institutional outreach ... Multiple methods of dissemination might be used if health campaigns are part of a broader social marketing programmes"(2010: 1261).
\end{abstract}

If media campaigns are a part of the social marketing programmes, broad dissemination methods and channels and formats should be used by the social marketers. But when increasing the number of communication formats and the media channels, it shoul be noted that the 'integration of these channels to achive a one sight - one sound effect' is rather important. The twofold integration efforts include to 'orchestrate the delivery of messages into the marketplace' and to'apply the strengths of each communication discipline or technique so that the whole is greater than the sum of the parts and the optimal message impact is achieved' (Cited from Schultz and Schultz by Cheng et al., 2011: 10). When these ends are achieved we can refer to a successful media campaign that is the part of social marking programme.

\title{
5. A Success Story of Social Marketing: The Anti- Tobacco Campaign in Turkey
}

Turkey had a serious problem of smoking and tobacco use prevailing in its adult population during the recent years but could not overcome this problem and failed to complete legislations concerning tobacco control. It had the highest tobacco use prevalence levels in Europe and was home to tobacco growers (Adams, 2012). All these aspects contributed to a society of ill-health suffering from chronical diseases. According to Nazmi Bilir, professor of public health, tobacco use climbed among Turkish population with the arrival of ad icons and their counterparts in the 1980s. The next two decades saw the doubling of tobacco use with sales going up to 98 billion Turkish Lira (US\$ 55 billion) to more than 178 billion Turkish Lira (US\$ 100 billion) in 2000. Therefore, this brought the toll of the five million patients hospitalized in Turkey in 2000, $20 \%$ of which had a smoking induced disease such as cardiovascular conditions and 'accounted for more than half of all hospital deaths'(Adams, 2012).

Although the first tobacco control law was signed in 1996 and the parliament approved World Health Organization Framework Convention on Tobacco Control (WHO FCTC) in 2004, nothing seemed to change when it was the year 2006:

\begin{abstract}
"According to a government survey of tobacco use conducted in 2006, some 33\% of adults were daily smokers, including just over half of all men and approximately $16 \%$ of women aged 18 and over. In a Gallup poll conducted in 100 countries the following year, two out of three Turkish men said they had lit up the day before they were surveyed, as did one out of three women. That was, Gallup said, "by far the highest incidence reported". It also confirmed a stereotype common to countries across Europe: that to smoke heavily was "to smoke like a Turk" (Adams, 2012).
\end{abstract}

Tobacco use had the highest incidence in Turkey throughout the Europe in 2006. On May 192008 the law passed that banned the use of tobacco in indoor spaces. A national media campaign was launched to increase public awareness against smoking and tobacco use. A unit established in the Ministry of Health to carry out the national tobacco control programme and action plan. The slogans "Smoke-free Air Zone" and "Save your Air" were developed for the campaign. Increasing awareness on second hand smoke was also aimed. A uniting approach was aimed for the media campaign. A web site was designed to inform the public against tobacco use and second hand smoke. The ministry of Health along with WHO, UNION, CTFK helped to increase public awareness against tobacco use. Media advocacy was sought to spot broadcasting, and billboards and posters, print media magazines and news papers. A support line was established for smokers which is called "Alo 171 - Ouit line" (www.havanikoru.org.tr).

As noted by Dağlı, media was not very keen on helping this campaign until the legislation was enacted:

"Yet, it wasn't only the industry Dağli and colleagues were up against. "We were fighting the media, too", she adds, citing newspapers' reliance on revenue from tobacco advertising as the main reason for their opposition to the 1996 law. "In a way, we were actually promoting tobacco when we held a press conference because the newspapers would 
call the tobacco companies and say 'Hey these health guys are organizing a meeting, do you want to buy an ad on the same page?' And the next day there would be a few lines about us next to a giant Marlboro man" (Adams, 2012).

As it clearly shows from the citation noted above a social marketing campaign was needed in order to integrate all parts of the society in the campaign and media advocacy was also needed to orchestrate all the messages delivered to the public.

The first phase of the campaign covered the dates May 142008 - June 18 2009. By the Smoke-free Air Zone Campaign a large public support was aimed. In order to promote public awareness the support of opinion leaders, artists and political party leaders were asked. The second phase covered the dates June 182009 and February 2010. Because the law would comprise the restaurants, cafes, bars in July 19 2009, the concept of \%100 Smoke-free Air Zone was developed. The emphasis was made on the harms of second hand smoke and display posters were used drawing attention to the issue. The third phase November 2010 focused on the deadly results of tobacco use and smokers are forwarded to National Support Line Alo 171 to seek help to quit smoking. In the campaign, role models, opinion leaders and political leaders acted as the spokespersons of the campaign reinforcing the message of unity and support.

When the strategies used in the campaign are examined it can be noted that it is a social marketing campaign which covers the strategies used in a social marketing campaign. Turkey used the lessons learned from other succesful social marketing campaigns. In this campaign, in order to achieve public health goals we see succesful development of the marketing mix. The core product in the campaign is; benefits of being a non smoker and not being exposed to second hand smoke, the actual product is to reject smoking and reject being exposed to second hand smoke. The augmented product is the information that makes target audience educated about smoking and tobacco use. As for price, an increase in price decreases cigarette use and giving prizes for non smokers. As for placement, banned smoking indoors and to create \%100 Smoke free Air Zone. Also, it is illegal for people under 18 to purchase cigarettes in Turkey. Ban on ads of tobacco in Turkey, is for promotion, and there is extensive usage of media with the help of media advocacy through various communication channels. That led to integration of messages to create one sound effect.

Turkey's social marketing campaign has proved very effective to quit smoking and exposure of non-smokers to second hand smoke. As a result, Turkey has been one of the top 15 countries that reduced Tobacco use. WHO encourages the other member states to follow Turkey's example. WHO had devised MPOWER package that includes monitoring measures for tobacco use (see Figure 2). WHO's MPOWER package concentrates on monitoring tobacco use and prevention policies; protecting people from tobacco smoke; offering help to quit tobacco use; warning about the dangers of tobacco; enforcing bans on tobacco advertising, promotion and sponsorship; and raising taxes on tobacco products.

Figure 2. Measures of MPOWER

$$
\begin{aligned}
& \text { Monitor tobacco use \& prevention } \\
& \text { policies } \\
& \text { Protect people from tobacco smoke } \\
& \text { Offer help to quit tobacco use } \\
& \text { Warn about the dangers of tobacco } \\
& \text { Enforce bans on tobacco advertising, } \\
& \text { promotion, \& sponsorship } \\
& \text { Raise taxes on tobacco }
\end{aligned}
$$

Source: GATS Fact Sheet Turkey 2012.

Turkey became one of the countries that enacted Mpower criteria for reducing tobacco use in the World. In order to monitor tobacco use and prevention policies Turkey made research on monitor policies through Global Adult Tobacco Survey, Global Youth Tobacco Survey and Health Professionals Tobacco Use survey. In terms of protecting people from tobacco smoke Turkey became a $\% 100$ smoke free by banning the use of tobacco in indoor spaces. In offering help to quit tobacco use; National support and quitline 171 services were established. Warning about the dangers of tobacco, all TV channels have an obligation of broadcasting programs and spots not less than 90 minutes a month since 1996 and with the addition of new material it is implemented succesfully. On the cigarette packs messages such as "smoking kills", 
"smoking seriosly harms you and others around you", "health instiutions can help you stop smoking", "smoking causes ageing of the skin", "smoking can cause a slow and painful death", "smoking can cause a strong addiction do not start it", "smokers die younger" is printed since 2008 and pictures are also added in 2010. Enforcing bans on tobacco advertising promotion and sponsorship: All kinds of advertising promotion and sponsorship on tobacco was banned by law in 1996. Raising taxes on tobacco; total tax on tobaccco is \%75 which was recommended by WHO (Bilir and Özcebe, 2013: 1). Therefore Turkey is considered successful in meeting the MPOWER criteria.

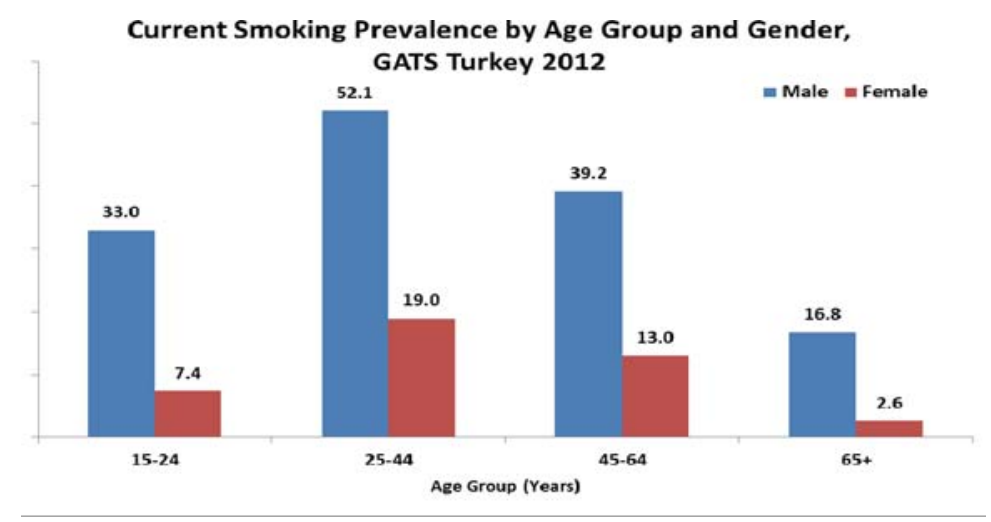

Source: GATS Fact Sheet Turkey 2012.

GATS is the The Global Adult Tobacco Survey which is a global standard for systematically monitoring adult tobacco use and tracking key tobacco control indicators. GATS is a national survey that represents Turkey across other countries. GATS helps countires to improve their capacity in designing and implementing tobacco control programs (www.who.int). When we look at GATS survey 2012 in Turkey, it is conducted as ahousehold survey among persons aged 15 and above by TURKSTAT (Turkish Statistics Institute) with the coordination of Ministry of Health:

"A multi-stage, geographically clustered sample design was used to produce nationally representative data. A total of 11,536 households were sampled and one individual was randomly selected from each participating household to complete the survey. Survey information was collected electronically by using netbooks. There were a total of 9,851 completed individual interviews with an overall response rate of \%90.1"(www.who.int).

According to the survey tobacco use showed a daily frequency of $41.5 \%$ of men, $13.1 \%$ of women, and $27.1 \%$ overall (14.8million adults). Tobacco cessation shows a range of $27.2 \%$ of ever daily smokers that have quit smoking and $42.9 \%$ of smokers visited a health care provider in the past 12 months and they were advised to quit. The remaining $55.2 \%$ of current smokers planned to or were thinking about quitting. In terms of second hand smoke, $15.6 \%$ of adults who worked indoors (2.4 million adults) were exposed to tobacco smoke at the workplace, 38.3\% of adults (20.8 million adults) were exposed to tobacco smoke at home. $26.4 \%$ of adults who own private cars (5.3 million adults) were exposed to tobacco smoke in private cars, $12.9 \%$ of adults (2.8 million adults) were exposed to tobacco smoke when visiting restaurants. When economics is considered the average monthly expenditure for manufactured cigarettes was 146.10 Turkish lira [81.12 USD]. On behalf of the out comes of the media campaign $92.0 \%$ of adults noticed anti-cigarette information on the television or radio and $94.3 \%$ of current smokers noticed health warnings on cigarette packages and $53.0 \%$ of current smokers thought about quitting as a result of seeing the warnings. If we look at changing knowledge attitudes and perceptions ' $96.2 \%$ of adults believed smoking causes serious illness. $96.2 \%$ of adults believed exposure to second hand smoke causes serious illness. 95.5\% of adults favor the law prohibiting smoking inside workplaces and public places'. That means the campaign has become successful in changing attitudes and perceptions (www.who.int).

Therefore; the achieved success is awarded by World Health Organization. The Minister of Health in 2008, the Prime Minister in 2010, and the President of Health Commission of Turkish Grand National Assembly in 2012. They received three World Health Organization awards to protect Turkish citizens from tobacco smoke in a short time. And lastly, in May 31, 2013 in Turkey received another award in World No Tobacco Day (www.havanikoru.org.tr). 


\section{Conclusion}

Social marketing is a popular subject that reflects the changing nature of societies. The strategies that meet the needs of changing societies social marketing looms large among them. In creating public awareness and achieving social ends social marketing takes the floor by enlarging the concept of marketing to encompass public health. In Turkey, campaigns that were launched before to create public awareness and to prevent tobacco use in the society remained as mere media campaigns that could not promote public health.But the recent campaign on tobacco use is an effective social marketing campaign that included the marketing mix and creating a perfect synergy to achieve that social end. The marketing mix made it possible to include all the elements of an effective campaign with right policies and media advocacy. Therefore, it is important to notice that social marketing principles made it possible for Turkey to achieve a successful campaign on tobacco use and create public awareness.

\section{References}

Adams, Patrick (2012), "Turkey's Transformation", Bulletin of the World Health Organization, 90 (6), http://www.who.int/bulletin/volumes/90/6/12-030612/en/index.html, (Accessed 27.06.2013).

Bilir, Nazmi and Özcebe, Hilal (2013), "Türkiye MPOWER Koşullarını Ne Kadar Karşılamaktadır?" TAF Preventive Medicine Bulletin, 12(1).

Cheng, Hong; Kotler, Philip and Lee, Nancy (2011), Social Marketing for Public Health - Global Trends and Success Stories, Jones and Bartlett Publishers, Sudbury -Masachussets.

Evans, W. Douglas (2006), "How Social Marketing Works in Healthcare?", BMJ, 332.

Kotler, Philip and Lee, Nancy R. (2009), Upand Out of Poverty: The Social Marketing Solution, Wharton School Publishing.

Kotler, Philip; Roberto, Ned and Lee, Nancy (2002), Social Marketing: Improving the Quality of Life, Sage Publications, Thousand Oaks California.

Kotler, Philip and Zaltman, Gerald (1971), "Social Marketing: An Approach to Planned Social Change", Journal of Marketing, 35.

"Social Marketing", American Marketing Association, http://www.marketingpower.com/_layouts/dictionary.aspx?dLetter=S (Accessed 01.07.2013).

Wakefield M.A, Loken B, Hornik Robert C. (2010) "Use of Mass media Campaigns to Change Health Behaviour" The Lancet, Vol 376. Walsh, D.C.; Rudd, R.E.; Moeykens, B.A. and Moloney, T.W.(1993), "Social Marketing for Public Health", Health Affairs, 12 (2).
WHO
(2013)
"GATS:
Global
Adult Tobacco
Survey
Facts Sheet
Turkey
2012", http://www.who.int/tobacco/surveillance/survey/gats/gats_turkey_2012_fact_sheet_may_2013.pdf, (Accessed 28.06.2013).

WHO (2012), "Turkey Marks Progress in Fighting Against Noncommunicable Diseases", http://www.who.int/features/2012/ ncd_turkey/en/, (Accessed 28.06.2013).

http://www.havanikoru.org.tr/index.php/haberler/61-dunya-tutunsuz-gununde-turkiyeyi-gururlandiran-tablo.html (Accessed 27.06.2013). 